\title{
PERCEPÇÃO DOS ALUNOS SOBRE APORTES PEDAGÓGICOS PRÉVIOS ÀS AULAS E O DESAFIO PARA PROFESSORES
}

Carla Eliana Todero Ritter-cetodero@gmail.com

Centro Universitário UniFTEC

Rua Gustavo Ramos Sehbe, 107. Bairro Cinquentenário

CEP 95012-669 Caxias do Sul - RS

Resumo: As estratégias de ensino que conduzam cada vez mais estudantes na busca do sólido aprendizado permeiam a necessidade de mudanças no fazer pedagógico. Quando se trata da sala de aula invertida, sua configuração sugere o uso de aportes pedagógicos onde o estudante possa estar em contato com o objeto de estudo previamente às aulas presenciais, fazendo-o por meio virtual. Esse aporte pedagógico, ofertado e sugerido pelo professor exige esforço e compromisso de ambos os sujeitos do cenário. No presente trabalho, avaliou-se a percepção dos alunos da disciplina de Química sobre cinco aportes de estudos prévios às aulas ofertados pela instituição de ensino: videoaulas online, monitoria com estudante, monitoria com professor, acesso à biblioteca virtual com indicação de capítulos específicos de livros e a realização de questionários prévios às aulas presenciais. Esses aportes tinham como finalidade o contato inicial com o conteúdo conceitual a fim de que o momento de aula fosse de desenvolvimento de habilidades complexas e de aptidões. Os alunos avaliaram como positivas as propostas da instituição e a adesão por videoaulas foi significativa. $O$ uso de questionários prévios às aulas apresentou maior adesão do grupo de estudantes. Conhecer as necessidades dos estudantes e as peculiaridades das disciplinas e cursos permite que sejam selecionadas as formas de intervenção prévias às aulas quando a estratégia da sala de aula invertida for escolhida como proposta metodológica.

Palavras-chave: Aportes Pedagógicos. Habilidades. Competências. Sala de Aula Invertida. 


\section{INTRODUÇÃo}

A formação do engenheiro além de contemplar os conteúdos conceituais e técnicos, exige que habilidades essenciais sejam desenvolvidas, dentre elas a do contínuo aprender. Essa habilidade também é comum para os professores e gestores dos cursos de Engenharia na busca do fazer pedagógico de qualidade e que cada vez mais atenda às múltiplas exigências do mundo contemporâneo.

Em um modelo de sistema que preconiza a instrução, a definição dos objetivos de aprendizagem e das estratégias, bem como as tarefas de avaliação são definidos pelos professores que consideram a motivação para o aprender intrínseca e que alguns fatores externos podem influenciar de modo a "incentivar" o aprender. Ao encontro desta posição, um sistema construtivo avalia o contexto onde o aluno e o objeto do conhecimento estão em sintonia e os objetivos de aprendizagem possuem infraestrutura institucional para a ocorrência, priorizando as melhores práticas pedagógicas (Viana, 2017).

Associadas às melhores práticas, a definição da metodologia de ensino utilizada pelo professor, reflete muito da sua concepção do que é educar. No ensino de engenharia, metodologias que privilegiem o fazer associado à construção do conhecimento, desenvolvem habilidades ainda mais complexas, deixando para trás o lembrar para atingir habilidades de criação e análise.

Uma estratégia que contempla a metodologia do fazer associada à teoria é a aula invertida, embasada em momentos de estudo prévios aos de aula, onde o aluno tem contato com o material pedagógico fora da classe, geralmente através de leitura ou de videoaulas. Diferentemente da tradicional tarefa escolar, assistir às aulas on-line ou a leitura de um capítulo de livro, pressupõe-se que o estudante utilize esse momento prévio para a assimilação do conteúdo bruto, deixando para a aula, momentos de habilidades mais complexas como a resolução de problemas, debates e discussões (Brame, 2013).

O material didático em formato digital ofertado previamente para o estudante, segundo Corrêa (2013) é uma forma de dar continuidade à pesquisa e promoção do aprendizado de forma autônoma. As características desse material são a facilidade de interpretação e permissão de adaptações e atualizações. Cabe aqui o olhar atento do professor a fim de selecionar e indicar para o estudante algumas dessas possibilidades de interação com o objeto do conhecimento previamente às aulas.

Assim, muitas são as maneiras de proporcionar o estudo prévio à aula para o estudante a fim de tornar o momento da aula como propulsor de habilidades complexas. Neste presente artigo, avaliou-se a percepção dos estudantes da disciplina de Química quando da oferta de cinco aportes de estudos prévios às aulas ofertados pela instituição de ensino: videoaulas online, monitoria com estudante, monitoria com professor, acesso à biblioteca virtual com indicação de capítulos específicos de livros e a realização de questionários prévios às aulas presenciais.

\section{PROCEDIMENTO METODOLÓGICO}

A pesquisa apresentada caracteriza-se por ser aplicada e qualitativa. O estudo foi conduzido em uma turma que cursava a disciplina de Química no ano de 2019, ofertada no turno da noite para os estudantes de primeiro semestre dos cursos de Engenharia do Centro Universitário. Como opção de distintos momentos pedagógico para estudos prévios às aulas presenciais, no ambiente virtual de aprendizagem, os alunos tiveram à disposição videoaulas 
sobre os temas a serem abordados na aula, questionários prévios, indicações de leituras em livros da biblioteca virtual e a indicação de construção de mapas conceituais. Também foi ofertada a monitoria com professor da área de conhecimento em dois turnos e monitoria com estudantes de Graduação em três turnos distintos aos da aula presencial.

A professora de Química orientou, no início do semestre, a participação nos aportes pedagógicos disponibilizados e da obrigatoriedade da resolução dos questionários prévios. Os mesmos ficavam disponíveis para os alunos por $1 \mathrm{~h}$ antes do período da aula e sempre referiam-se ao conteúdo visto na aula anterior e nas videoaulas prévias.

A avaliação da percepção dos alunos foi realizada em uma turma, de 32 alunos, estudantes do turno da noite, com idade média de 22 anos, sendo que 90\% trabalhavam durante o dia.

\section{RESULTADOS E DISCUSSÃO}

Com o intuito de avaliar o envolvimento dos alunos nos aportes pedagógicos prévios à aula presencial, foram questionados sobre quais disponíveis no ambiente virtual de aprendizagem eram mais utilizados. Das respostas coletadas, $70 \%$ deles avaliaram que as videoaulas referentes às aulas eram tidas como recurso de maior aceitação para estudo prévio. A leitura de capítulos de livros configurou apenas $10 \%$ das escolhas dos alunos para prepararse para a aula presencial e a realização dos questionários prévios, $20 \%$.

Em relação ao acesso prévio às videoaulas, $40 \%$ dos alunos assistiram mais de $70 \%$ das disponíveis previamente. Entretanto, 40\% dos alunos assistiram de 10 a $30 \%$ delas, denotando que quase a metade da turma, não apresentava engajamento mínimo sobre o tema (Figura 1).

Figura 1- Resposta dos alunos em relação à pergunta: Qual o percentual de videoaulas você assistiu antes da aula presencial?

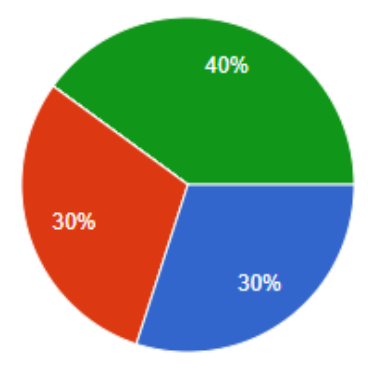

$$
\begin{aligned}
& \text { de } 10 \text { a } 30 \% \\
& \text { de } 30 \% \text { a } 50 \% \\
& \text { de } 50 \% \text { a } 70 \% \\
& \text { mais de } 70 \%
\end{aligned}
$$

Dentre os motivos apresentados pelos estudantes que não assistiram às videoaulas pode-se citar: indisponibilidade de associar o tempo de trabalho com o de estudo (85\%), doença durante o período (5\%) e exigências de outras disciplinas (10\%).

Quando os estudantes afirmam que a falta de tempo para a participação em monitorias (Figura 3) foi determinante, Zimmerman e Risemberg (2013) afirmam que as tarefas propostas pelos professores em diferentes âmbitos educacionais devem permitir que os mesmos tomem decisões pessoais regulatórias em seus processos de aprendizagem. Para o autor:

"os processos de aprendizagem de um estudante e as crenças motivacionais que o acompanham se enquadram em três (3) fases autorrregulatórias: planejamento, execução e autorreflexão. Os processos da fase de planejamento são usados na preparação para a fase de execução, durante a 
qual o estudante empreende esforços para controlar e observar o seu próprio aprendizado. Os processos da fase de autorreflexão ocorrem após a execução das tarefas de aprendizagem, visando otimizar as reações do estudante aos seus resultados. Essas reações, por sua vez, influenciam os processos de planejamento e as crenças quanto aos esforços necessários nas tarefas subsequentes, completando um ciclo de autorregulação."

Como atividade prévia à aula presencial, também foram ofertados momentos para construção de mapas conceituais após a leitura de um subcapítulo de um livro e a resolução de exercícios envolvendo os temas estudados. Os alunos avaliaram o seu desempenho como bom (50\%), mas outros $40 \%$ avaliaram como regular (Figura 2).

Sobre a autoavaliação e a autorregulação da aprendizagem, Silva (2018) em estudos de Nicol e Macfarlane-Dick (2006) propõe que o feedback dado pelo professor durante as aulas precisa ser constante. Para o autor, o feedback:

\begin{abstract}
"Ajuda a esclarecer o que é um bom desempenho: em ambientes acadêmicos, entender o que é um bom desempenho significa que deve haver um grau razoável de sobreposição entre as metas definidas pelo discente e as metas, originalmente, estabelecidas pelo professor. Dessa maneira, o feedback deve esclarecer as metas, os critérios e os resultados esperados nas atividades.

Facilita o desenvolvimento da autoavaliação: assim como é importante envolver o estudante na identificação dos critérios aplicados nas atividades, e interessante conceder informações para que o discente faca julgamentos dos seus resultados em relação a esses critérios."
\end{abstract}

Figura 2- Respostas dos alunos quando questionados sobre o seu desempenho na construção de mapas conceituais e na realização de exercícios prévios à aula.

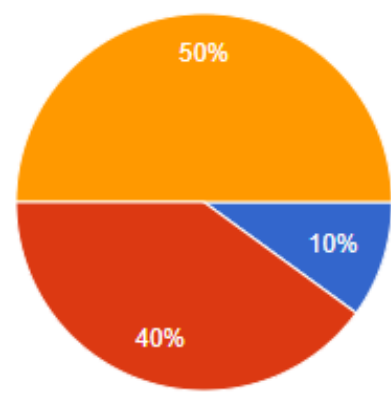

Ruim, pois não realizei as tarefas solicitadas

Regular, pois realizei me parte as atividades solicitadas

Boa, pois envolvi-me com as atividades fornecidas para aprimorar meu estudo.

Além das atividades prévias às aulas presenciais e a fim de estimular o conhecimento e a discussão de temas, foi ofertado monitoria para os alunos da disciplina em três turnos, em horário vespertino, distintos aos da aula. Os objetivos das monitorias foram a oportunidade de discussão de temas e a solução de dúvidas sobre os assuntos abordados em aula. Observouse que $90 \%$ deles não compareceram (Figura 3). Como justificativa à ausência, constatou-se que a falta de tempo para a frequência (75\%), períodos concomitantes às outras aulas $(8 \%) \mathrm{e}$ outros fatores como transporte e horários extras nas empresas $(17 \%)$ foram elencadas. 
Figura 3- Resposta dos alunos sobre o comparecimento às monitorias.

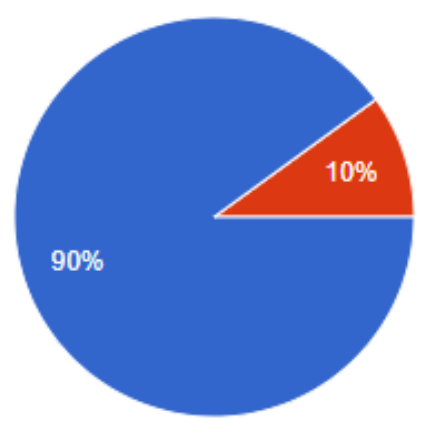

Não compareci.

Não tive interesse.

Compareci em uma ou duas vezes

Compareci em mais de duas vezes.

A percepção dos alunos frente aos diferentes aportes pedagógicos para a busca na excelência no ensino oportunizadas na discplina de Química, foram avaliadas a partir do questionamento: A partir da disponibilidade de diferentes estratégias de ensino, a construção de mapas mentais nos inícios das aulas, os questionários prévios e as atividades em grupos em aula, avalie os aportes pedagógicos ofertados na disciplina. Algumas repostas dos alunos foram citadas:

- O método de forma geral foi satisfatório, porém o excesso de conteúdo para pouco tempo de aula, deixou, de certa forma, prejudicada a aprendizagem (Aluno 1).

- Particularmente, tenho maior facilidade em fixar os conteúdos em aula presencial, porém as videoaulas ajudam os alunos a não irem tão perdidos para a aula (Aluno 2).

- Muito boa, as atividades da monitoria ajudam muito e muitas vezes nessa conversa acabamos apreendendo outra maneira de resolver uma questão ou um problema, algo que contribui bastante no raciocínio lógico do aluno. (Aluno 3).

Pela resposta do aluno 1 que coloca no excesso de conteúdo como o impeditivo para uma melhor aprendizagem, Marin et al (2010) afirmam que a mudança abrupta de métodos de ensino pode deixar os alunos perdidos na busca de conhecimento, tendo a sensação que os conteúdos foram pouco explorados. Nesse contexto, os autores ainda reforçam que os conteúdos devem ser construídos pelo estudante, que precisa reorganizar o material, adaptando-o à sua estrutura cognitiva prévia, para descobrir relações, leis ou conceitos que precisará assimilar. Destacam que dessa forma a aprendizagem se torna significativa e duradoura, fazendo com que o estudante adquira o desejo de aprender e se torne estimulado a produzir o próprio conhecimento.

Sobre a validação do uso de questionários prévios à aula, o grupo de estudantes assinalou como positiva a estratégia, evidenciada pelo número de alunos por turma que realizou a atividade: cerca de $70 \%$.

Silva (2018) sobre o as formas de engajar os alunos nas atividades prévias às aulas, cita Valente (2014): 


\begin{abstract}
"Uma forma de mudar o comportamento dos estudantes que não se preparam antes das aulas é agregar, nas atividades a distância, tarefas com impacto sobre a avaliação formal. A atribuição de nota, provavelmente, estimulará os discentes a realizarem esse tipo de atividade. Mas, ainda assim, sem a capacidade de autorregularão, os estudantes podem enfrentar muitas dificuldades."
\end{abstract}

Percebe-se como um grande desafio para professores e gestores promover o completo engajamento dos estudantes com o estudo de excelências, despertando para a necessidade do desenvolvimento de aptidões. No contexto atual de mudanças nos formatos de ensinar e aprender pode evidenciar alguns deslocamentos frente aos conflitos, pausas e invenções do ser docente. $\mathrm{O}$ desvencilhamento dos processos a serem rompidos no emaranhado epistemológico, ainda vigente na contemporaneidade, requer compreender o processo de poder, oriundo da bipartição sujeito-objeto. O estudar prévio ao momento da "aula" requer rompimento da cultura passiva do estudante e de transmissor por parte do professor.

Silva (2018) destaca que a sala de aula invertida se apresenta como uma proposta em dois blocos: uma com atividades interativas em grupo, durante a aula presencial, e outro com instrução individual, com o auxílio das tecnologias digitais (Figura 4). Segundo o autor, há algumas dificuldades percebidas pelos professores na implementação da sala de aula invertida no que se refere ao planejamento prévio às aulas. A dificuldade reside no domínio de técnicas de edição de materiais, aquisição de equipamentos e tempo dedicado à realização dessas tarefas. Além disso, o desenvolvimento de atividades de avaliação exige do professor uma preparação prévia, constante e significativa.

Figura 4- Partes da sala de aula invertida (adaptado por Bishop e Verleger, 2013).

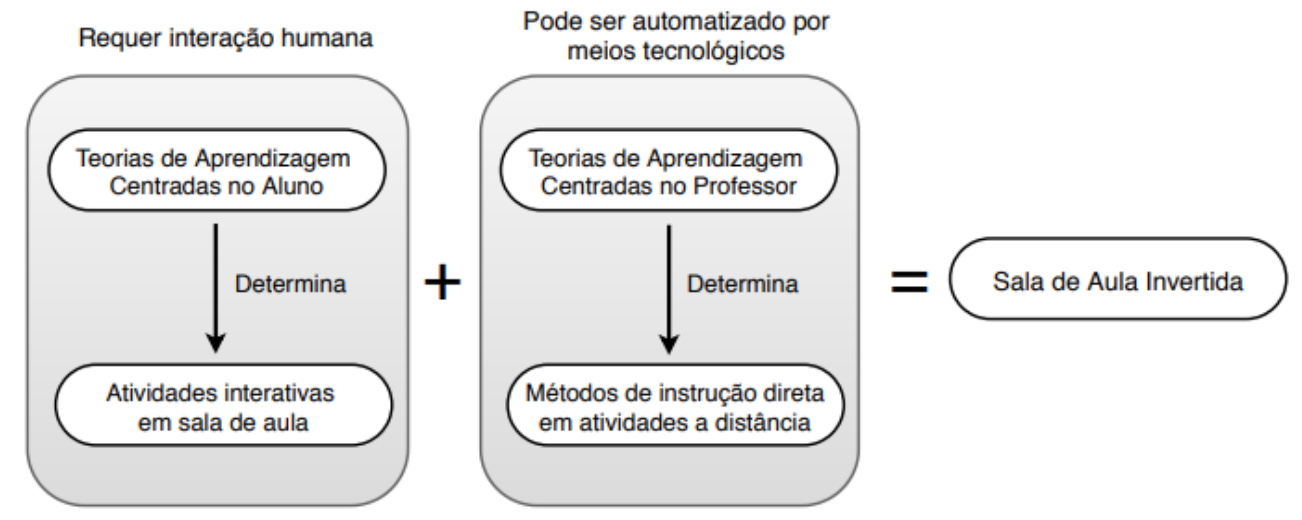

Nesse contexto, percebe-se que o professor é o articulador do conhecimento e gestor da caminhada de aprendizagem do aluno, uma vez que as fronteiras do conhecimento ultrapassam os conteúdos conceituais de uma determinada disciplina curricular. Assim, a autonomia do estudante deve ser monitorada a fim de evitar que interprete de maneira errônea a abordagem pedagógica e não se prepare adequadamente para as discussões presenciais em aula. 


\section{CONSIDERAÇÕES FINAIS}

A partir da pesquisa realizada observou-se que dentre os aportes pedagógicos oferecidos para os estudantes da disciplina de Química durante o semestre letivo para estudo prévio às aulas presenciais, as videoaulas apresentaram maior aceitação, sendo assistidas com frequência. $\mathrm{O}$ acesso às monitorias por professor e alunos não se mostrou como uma opção viável para os estudantes que trabalham durante o dia, pois argumentaram não possuírem tempo para participarem.

O desafio dos professores para implementação de momentos prévios de estudos antes das aulas presenciais para a estratégia da sala de aula invertida existe e pode ser ajustado na medida que se conhece as necessidades dos estudantes, que se diferem de curso para curso e de disciplina para disciplina.

A adesão na resolução de questionários prévios foi satisfatória e demonstrou-se ser possível para o estudo prévio às aulas.

\section{REFERÊNCIAS}

BRAME, C. Flipping the classroom. Vanderbilt University Center for Teaching. 2013.

CORRÊA, M. A. Os materiais didáticos como recursos fundamentais de potencialização da qualidade do ensino e aprendizagem na EaD. In: E-Tech: Tecnologias para Competitividade Industrial, Florianópolis/SC, v. 6, n. 1 p. 125-140, 2013.

MARIN, M. J.; Aspectos das fortalezas e fragilidades no uso das metodologias ativas de aprendizagem. Revista Brasileira de Educação Médica (online) 2010, vol. 34, n. 1, pp. 1320. 2010

SILVA, João Carlos Sedraz. Uma Abordagem de Learning Analytics para a Autorregulação da Aprendizagem de Estudantes em Sala de Aula Invertida. Tese (Doutorado) apresentada na Universidade Federal de Pernambuco. Pernambuco. 2018. https://repositorio.ufpe.br/handle/123456789/29849

VIANA, A.B.N. Taxonomia das metodologias ativas com base na taxonomia de Bloom. In---: JUNQUEIRA, L.A.P.; PADULA, R.S. (orgs). Aprendizagem no Ensino Superior no século XXI: desafios e tendências. São Paulo: Tiki Books. 352p., 2017.

VALENTE, José Armando. Blended learning e as mudanças no ensino superior: uma proposta da sala de aula invertida. Educ. rev. [conectados, pp.79-97. Disponível em: <http://www.scielo.br/scielo.php?script=sci_arttext\&pid=S0104-

$40602014000800079 \& \operatorname{lng}=$ en\&nrm=iso . 2014

ZIMMERMAN, B. J. From cognitive modeling to self-regulation- A social cognitive career path. Educational psychologist, v. 48, n. 3, p. 135-147, 2013.

\section{PERCEPTION OF STUDENTS ABOUT PREVIOUS PEDAGOGICAL SUPPORT TO CLASSES AND THE CHALLENGE FOR TEACHERS}

Abstract: Education strategies that lead more and more students in search of solid learning permeate the need for changes in pedagogical practice. When it comes to the inverted classroom, its configuration suggests the use of pedagogical contributions where the student can be in contact with the object of study prior to the face-to-face classes, doing it through 
virtual means. This pedagogical contribution, offered and suggested by the teacher requires effort and commitment from both subjects in the scenario. In the present work, the perception of students of the Chemistry discipline about five contributions of studies prior to classes offered by the educational institution was evaluated: online video classes, student monitoring, teacher monitoring, access to the virtual library with indication of specific chapters of books and the realization of questionnaires prior to face-to-face classes. These contributions were intended to make the initial contact with the conceptual content so that the moment of class was to develop complex skills and aptitudes. The students rated the institution's proposals as positive and the adhesion by video classes was significant. The use of questionnaires before classes also showed adherence by the group of students. Knowing the needs of the students and the peculiarities of the disciplines and courses allows the forms of intervention prior to classes to be selected when the inverted classroom strategy is chosen as a methodological proposal.

Keywords: pedagogical support, skills, flipped classroom. 